Available online at https://jurnal.stmikroyal.ac.id/index.php/jurdimas

\title{
PELATIHAN HIDROPONIK DI YAYASAN ASOFA AKSELERASI SODAQOH FIQRUL AKBAR, KAB. BEKASI
}

\author{
Annisa Nur Ichniarsyah ${ }^{1 *}$, Heny Agustin ${ }^{1}$, Maulidian ${ }^{2}$ \\ ${ }^{1}$ Agroekoteknologi, Universitas Trilogi, Jakarta \\ ${ }^{3}$ Agribisnis, Universitas Trilogi, Jakarta \\ email:*annisanur@trilogi.ac.id
}

\begin{abstract}
: urban farming means to cultivate and nurture animals in a city or within its rural area. There are variety of plants that could be grown namely vegetables and fruits. Urban agriculture is expeted to help improve the economy of the people in an area because the yields produced can provide economic benefits. The Asofa Foundation tried to capture this opportunity in the context of developing a masjid-based economy through hydroponic training for the surrounding community. Therefore, a series of training was conducted to improve the capacity of the community. The training included training on seeding vegetables in rockwool, training on transplanting, and training in preparing and mixing hydroponic fertilizers. The results of the training were that residents were able to cultivate plants using hydroponics. However, the boundary was the environmental conditions (in this case water) in Bekasi which were not good enough so that the seedlings died after being transplanted into the hydroponic kit. Further training needed can be in the form of training fruit plants using hydroponics which can withstand inadequate water conditions. Another training that can be carried out is training in vegetable cultivation with planting methods other than hydroponics that are able to accommodate environmental conditions
\end{abstract}

Keywords: urban farming, economic development, masjid-based economy, trainings

\begin{abstract}
Abstrak: Pertanian perkotaan adalah menanam dan memelihara binatang ternak di dalam atau sekitar kota. Beragam jenis tanaman dapat dibudidayakan terutama tanaman sayuran dan buah. Pertanian perkotaan mampu membantu peningkatan ekonomi rakyat di suatu daerah karena hasil panen yang dihasilkan dapat memberikan keuntungan ekonomis. Peluang inilah yang berusaha ditangkap oleh Yayasan Asofa dalam rangka pengembangan ekonomi berbasis masjid lewat pelatihan hidroponik untuk masyarakat sekitar. Oleh karena itu, dilakukanlah serangkaian pelatihan untuk meningkatkan kemampuan masyarakatnya. Pelatihan yang dilakukan antara lain pelatihan penyemaian tanaman sayuran di rockwool, pelatihan pindah tanam, dan pelatihan meracik pupuk hidroponik. Hasil dari pelatihan tersebut adalah warga mampu melakukan budidaya tanaman dengan menggunakan hidroponik hanya saja kondisi lingkungan (dalam hal ini air) di daerah Bekasi kurang baik sehingga tanaman semaian mati setelah dipindahkan ke dalam kit hidroponik. Pelatihan lanjutan yang diperlukan dapat berupa pelatihan tanaman buah dengan menggunakan hidroponik yang tahan kondisi air yang kurang memadai. Pelatihan lain yang dapat dilakukan adalah pelatihan budidaya tanaman sayuran dengan metode tanam selain hidroponik yang mampu mengakomodasi kondisi lingkungan.
\end{abstract}

Kata kunci: pertanian perkotaan, pengembangan ekonomi, ekonomi berbasis masjid, pelatihan 
Available online at https://jurnal.stmikroyal.ac.id/index.php/jurdimas

\section{PENDAHULUAN}

Pertanian perkotaan atau urban farming dapat didefinisikan sebagai kegiatan budidaya tanaman, pengolahan dan pendistribusian bahan makanan di dalam atau di sekitar kota atau desa (Bailkley dan Nasr, 2000). Konsep pertanian perkotaan dan sarana yang termasuk di dalamnya semakin populer diperbincangkan dalam delapan tahun terakhir terutama dengan semakin meningkatnya kebutuhan masyarakat perkotaan terhadap bahan pangan yang berkualitas (Shamsiri et al., 2018). Konsep pertanian perkotaan cukup luas, sehingga berbagai aspek dapat dikategorikan sebagai pertanian perkotaan mulai dari kebun milik pribadi maupun komunitas lokal untuk tujuan sosial dan pemenuhan kebutuhan sendiri hingga sistem rumit yang melibatkan kegiatan budidaya tanaman dengan bantuan pencahayaan artifisial (Shamsiri et al., 2018). Berdasarkan definisi tersebut, pertanian perkotaan yang dimaksud adalah menanam dan memelihara binatang ternak di dalam atau sekitar kota. Beragam jenis tanaman dapat dibudidayakan terutama tanaman sayuran dan buah.

Merujuk pada hasil konferensi tingkat tinggi tentang Ketahanan Pangan yang dilaksanakan oleh FAO di Roma pada tanggal 3 - 5 Juni 2008, pertanian perkotaan merujuk pada tiga tujuan global yaitu (1) keberlanjutan peningkatan produksi dan ketersediaan pangan; (2) kemajuan ekonomi dan sosial; dan (3) keberlanjutan pengelolaan dan penggunaan sumberdaya alam. Pertanian perkotaan ini secara langsung berkontribusi pada ketahanan pangan, peningkatan nutrisi, dan penghidupan masyarakat (Pemprov DKI, 2017). Secara khusus, pertanian perkotaan memiliki beberapa manfaat, antara lain (1) akses makanan segar dan bergizi untuk masyarakat miskin tanpa melalui pasar dan meningkatkan pendapatan mereka; (2) memasok pasar makanan di kota, makanan jalanan, dan pengolahan makanan serta menyediakan tambahan pekerjaan dan pendapatan; (3) panen air, penggunaan kembali air, dan penggunaan kembali limbah/sampah untuk menyediakan air, makanan ternak dan pupuk untuk pertanian kota; dan (4) meningkatkan partisipasi masyarakat kota, khususnya warga perempuan yang sudah banyak berkontribusi untuk ketahanan pangan (Hoornweg dan Munro-Faure, 2008).

Adapun pola pengembangan pertanian perkotaan adalah mengandalkan lahan tidur yang berada di tengah perkotaan dan pekarangan. Pekarangan adalah lingkungan di sekitar rumah yang dapat diusahakan untuk komoditas pertanian. Menanam tanaman yang produktif seperti tanaman hortikultura dapat memberikan keuntungan yang dapat memenuhi kepuasan jasmani dan rohani (Badan Litbang Pertanian, 2011). Pola lain yang dapat dikembangkan adalah kebun kolektif, yaitu pemanfaatan lahan milik Bersama di area pemukiman. Kegiatan ini dapat diusahakan secara kolektif lingkungan perumahan (Badan Litbang Pertanian, 2011).

Pola pengembangan pertanian perkotaan yang mampu mendukung peningkatan ekonomi ini mendorong Yayasan Fikrul Akbar melalui ASOFA (Akselerasi Sodaqoh Fikrul Akbar) untuk memberikan pembinaan dan pelatihan hidroponik kepada masyarakat sekitar. Adanya kegiatan ini diharapkan mampu membantu masyarakat yang telah mengikuti pelatihan sehingga mampu mengembangkan sendiri budidaya 
Available online at https://jurnal.stmikroyal.ac.id/index.php/jurdimas

dengan sistem hidroponik untuk kebutuhan hidup masing-masing.

\section{METODE}

Waktu pelaksanaan pengabdian dilakukan dari bulan September 2018 hingga Februari 2019 di Masjid Fatimah, Yayasan Fikrul Akbar, Kampung Babelan, Bekasi dan Laboratorium Lapangan Program Studi Agroekoteknologi, Universitas Trilogi, Jakarta.

Langkah pelaksanaan program berupa persiapan dan koordinasi, pelaksanaan, monitoring dan evaluasi, serta tindak lanjut.

Tahap persiapan dan koordinasi berupa persiapan dan penilaian kebutuhan dan masalah yang ada pada daerah mitra. Setelah melakukan pengamatan dan melihat potensi di wilayah tersebut maka dapat diketahui adanya lembaga yang akan menjadi wadah atau sarana pengembangan kegiatan.

Tahapan pelaksanaan diisi dengan sosialisasi dan pelatihan yang telah dirancang untuk solusi permasalahan yang ada di daerah mitra. Pelatihan dijadwalkan sekali tiap bulan. Selain kegiatan pelatihan juga dilakukan kegiatan pendampingan dan mentoring sehingga jika masyarakat menemui kesulitan dalam budidaya sistem hidroponik, masyarakat dapat berkonsultasi dengan pakarnya.

Kegiatan monitoring dan evaluasi dilakukan oleh pemimpin Yayasan Fikrul Akbar, serta dosen dan mahasiswa. Jika terdapat permasalahan maka masingmasing pihak dapat memberikan masukan yang memberikan perbaikan di masa mendatang.

Terakhir adalah tindak lanjut yaitu setelah kegiatan pengabdian masyara- kat selesai dilakukan, perlu adanya usaha-usaha tindak lanjut sehingga kegiatan dapat terus berjalan pada masa yang akan datang. Masyarakat diharapkan mampu melanjutkan program dan menyebarkan ilmu pengetahuan yang telah didapat ke masyarakat lain yang belum memperolehnya (Training of Trainer).

Pelatihan-pelatihan yang diberikan berupa teori dan praktik yang disusun secara sistematis sehingga dapat diterapkan agar hasilnya maksimal. Pelatihan tersebut antara lain: 1) Workshop tentang pertanian perkotaan pada umumnya dan hidroponik pada khususnya; 2) pelatihan penyemaian benih; 3) pelatihan meracik pupuk $\mathrm{AB}$ mix; 4) pelatihan transplanting dan persiapan kit hidroponik, 5) Pelatihan branding dan kemasan.

Peserta pelatihan merupakan angkatan pertama dari masyarakat Kampung Babelan yang memperoleh pelatihan hidroponik. Angkatan I ini diharapkan mampu menjadi trainer untuk angkatan-angkatan selanjutnya.

\section{PEMBAHASAN}

Sebelum melakukan kegiatan pengabdian, pemetaan kebutuhan dilakukan untuk mengetahui peminatan masyarakat di sekitar Masjid Fatimah, Kampung Babelan, Bekasi. Di dalam Kawasan Masjid Fatimah, telah terdapat 4 kit hidroponik namun sudah tidak berfungsi dengan baik. Kondisi kit hidroponik dan lokasi keberadaan kit yang telah ada dapat dilihat pada Gambar 1. 
Available online at https://jurnal.stmikroyal.ac.id/index.php/jurdimas

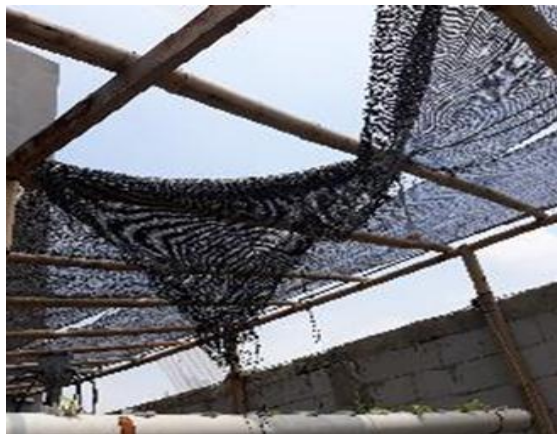

Gambar 1 Kondisi naungan hidroponik

Hasil dari pemetaan kebutuhan menunjukkan bahwa terdapat sekitar 30 warga yang berminat mempelajari tentang teknik hidroponik. Oleh karena itu, dilakukan pelatihan pendahuluan terkait budidaya tanaman dengan hidroponik pada tanggal 24 September 2018. Tingkat pemahaman warga tentang hidroponik cukup beragam yang ditunjukkan dengan adanya warga yang memiliki pemahaman cukup mendalam terkait hidroponik. Namun ada pula warga yang sama sekali belum memahami tentang budidaya tanaman dengan hidroponik. Oleh karena itu, peserta dibagi menjadi dua kelompok besar agar pemberian materi disesuaikan dengan tingkat pemahaman tentang hidroponik.

Pelatihan penyemaian benih dilakukan pada tanggal 24 Oktober 2018. Pada sesi pendahuluan, warga diberikan arahan terkait penyemaian dan cara penyemaian menggunakan teknik hidroponik. Kemudian, warga diberikan kesempatan untuk menyemai dan memilih sendiri tanaman yang akan disemai. Tiap warga diberikan rockwool atau media tanam hidroponik berukuran $15 \times 20 \mathrm{~cm}$ yang diletakkan di dalam baki semai dan melakukan praktik penyemaian sawi. Selanjutnya, setelah warga mendapatkan ilmu terkait penyemaian hidroponik yang baik, warga dilatih cara melakukan formulasi pupuk $\mathrm{AB}$ mix dengan tepat. Warga juga diberikan panduan tentang cara dan waktu pemberian pupuk $\mathrm{AB}$ mix yang tepat.

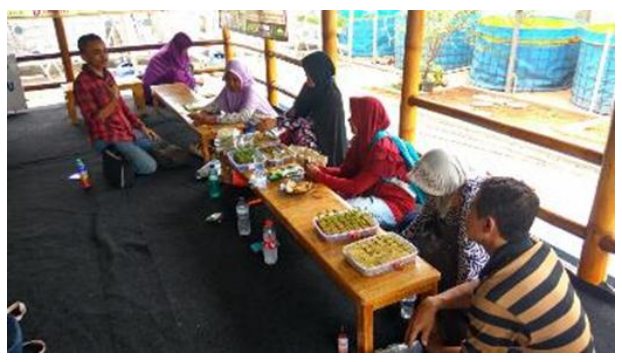

Gambar 2 Pelatihan racik $\mathrm{AB}$ mix

Akan tetapi, setelah dilakukan beberapa kali penyemaian, pertumbuhan tanaman sayuran yang disemai kurang baik. Tanaman sayuran menjadi kurus dan tidak memerlukan waktu lama, tanaman pun mati. Ketika dilakukan pengecekan kondisi air, ternyata diperoleh nilai EC dan ppm yang sangat tinggi yang dapat dilihat pada Gambar 5. Untuk mengatasi hal tersebut, digunakanlah air PAM yang berasal dari rumah warga yang lokasinya berada di depan masjid. Akan tetapi, karena masih kurangnya koordinasi antar warga, air yang sudah sesuai nilai EC-nya masih dicampur dengan air tanah yang nilai EC-nya kurang baik sehingga tanaman tidak dapat tumbuh dengan baik.

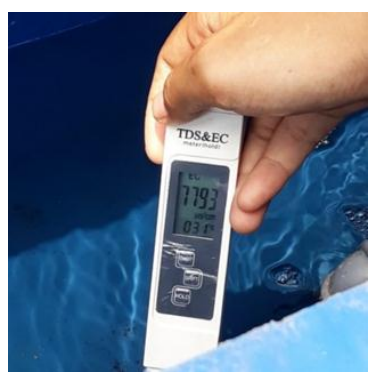

Gambar 3 Kondisi ppm air tanah di Kampung Babelan

Untuk mengetahui lebih dalam terkait kondisi air tanah yang berada di Kampung Babelan, dilakukan pengujian kandungan air di Laboratorium Pengujian 
Available online at https://jurnal.stmikroyal.ac.id/index.php/jurdimas

Kualitas Air, Jurusan Teknologi Industri Pertanian, Fakultas Teknologi Pertanian, Institut Pertanian Bogor. Hal ini dilakukan untuk mengetahui langkah yang harus diambil untuk mengatasi kondisi air yang kurang baik di Kampung Babelan. Kondisi air yang kurang baik tentu akan menyulitkan kegiatan budidaya dengan hidroponik yang sangat membutuhkan air berkualitas baik untuk kelangsungan pertumbuhan tanaman.

Hasil dari pengujian kualitas air yang dilakukan di Laboraturium Pengujian Kualitas Air, Jurusan Teknologi Industri Pertanian, Fakultas Teknologi Pertanian, Institut Pertanian Bogor menunjukkan angka daya hantar listrik yang cukup tinggi. Dua sampel air yang diperoleh dari air kran masjid dan air kran rumah warga di sekitar masjid menunjukkan angka 5,950 dan 2,450 $\mu \mathrm{s} / \mathrm{cm}$ secara berturut-turut. Hal ini menunjukkan tingginya kandungan elektrolit dalam air. Akibatnya, tanaman sayuran sulit untuk tumbuh dalam kondisi air yang memiliki nilai daya hantar listrik yang tinggi seperti itu. Inilah yang menyebabkan tanaman sayuran yang ditanam dengan sistem hidroponik kurang berhasil tumbuh.

\section{SIMPULAN}

Kegiatan pengabdian yang berlangsung di lingkungan Masjid Fatimah Kampung Babelan, Bekasi telah selesai dilakukan. Masih banyak hal yang perlu dikaji lebih dalam, salah satunya adalah budidaya tanaman sayuran menggunakan teknik hidroponik. Hasil pengujian di laboratorium menunjukkan bahwa daya hantar listrik dalam air cukup tinggi. Hal ini yang menyebabkan tanaman sayuran tidak mampu tumbuh dengan baik dengan menggunakan teknik hidroponik.
Oleh karena itu, penulis merasa perlu adanya pelatihan pengelolaan air untuk warga di Masjid Fatimah. Tujuan dari pelatihan ini adalah untuk memperbaiki kualitas air untuk tanaman yang akan ditanam dengan menggunakan teknik hidroponik.

Selain itu, hal lain yang dapat dilakukan adalah memilih komoditas tanaman sayuran atau buah yang cukup tahan dengan kondisi air yang kurang baik. Langkah tersebut dilakukan jika warga lebih memilih untuk mengembangkan komoditas tanaman lain yang sesuai dengan kondisi airnya. Oleh karena itu, penulis menyimpulkan bahwa perlu ada pelatihan budidaya tanaman yang tahan kondisi air yang kurang baik.

\section{UCAPAN TERIMA KASIH}

Penulis mengucapkan terima kasih kepada Universitas Trilogi karena melalui Hibah Pengabdian Universitas Trilogi maka kami dapat melakukan kegiatan pengabdian dengan lancar.

\section{DAFTAR PUSTAKA}

Badan Litbang Pertanian. 2011. Membangun Kemampuan Pengelolaan Lahan Pertanian Pangan Berkelanjutan. Bogor: IPB Press

Bailkey, M., dan J. Nasr. 2000. "From Brownfields to Greenfields: Producing Food in North American Cities," Community Food Security News. Fall 1999/Winter 2000:6

Hoornweg, Daniel dan Munro-Faure Paul. 2008. Urban Agriculture for Sustainable Poverty Alleviation and Food Security. Paper

Pemerintah Provinsi DKI Jakarta Kedeputian Gubernur Bidang Ta- 
Available online at https://jurnal.stmikroyal.ac.id/index.php/jurdimas

ta Ruang dan Lingkungan Hidup. 2017. Desain Besar Pertanian Perkotaan Provinsi DKI Jakarta 2018 - 2030.

Shamshiri, Redmond \& Kalantari, Fatemeh \& C. Ting, K \& Thorp, Kelly \& Hameed, Ibrahim \& Weltzien, Cornelia \& Ahmad, Desa \& Shad, Zahra. (2018). Ad- vances in greenhouse automation and controlled environment agriculture: A transition to plant factories and urban agriculture. International Journal of Agricultural and Biological Engineering. 11. 10.25165/j.ijabe.20181101.3210. 